\title{
Assessment of Cases of Anterior Cruciate Ligament Reconstruction Surgery- A Clinical Study
}

\author{
Shakti Condil Sharma ${ }^{1}$ \\ ${ }^{1}$ Assistant Professor, Department of Orthopaedics, SIMS Medical College, Pilakhua, Hapur.
}

\section{Abstract}

Background: The ACL is the primary restrain to anterior translation of the tibia on the femur. The present study was conducted to assess cases of anterior cruciate ligament reconstruction surgery in adult patients. Subjects and Methods: The present study was conducted on 72 patients who underwent anterior cruciate ligament reconstruction surgery. Risk factors were recorded. Results: Out of 72 patients, males were 48 and females were 24. Out of 72 patients, infection was present in 10 males and 4 females. Risk factors for ACL surgery was BPTB graft in 3, STG graft in 5 cases. Obesity was seen in 11, smoking in 6, and diabetes mellitus in 4. The difference was significant (P< 0.05). Conclusion: ACL injury is common among sports person. Risk factors reported were diabetes mellitus, smoking and obesity.

Keywords: Anterior cruciate ligament, Infection, Smoking.

Corresponding Author: Dr. Shakti Condil Sharma, Assistant Professor, Department of Orthopaedics, SIMS Medical College, Pilakhua, Hapur.

Received: September 2019

Accepted: September 2019

\section{Introduction}

Although much attention has been focused on noncontact ACL injuries in team sports, the exact mechanism of these injuries remains unclear. Understanding the joint kinematics and loading patterns that lead to injury is essential. ${ }^{[1]}$

The name "cruciate" is derived from the fact that these ligaments cross each other with anterior and posterior referring to their respective tibial attachments. These ligaments are termed intracapsular because they are located within the articular capsule and extrasynovial because they lie outside the synovial cavity. ${ }^{[2]}$ The ACL is made up of bundles of longitudinal fascicles that pass in lateral spiral rotation from femur to tibia. The femoral attachment on the medial surface of the lateral femoral condyle is a circular area tilted slightly forward from the vertical. The tibial attachment is in front and bilateral to the anterior tibial spine. ${ }^{[3]}$

The ACL is the primary restrain to anterior translation of the tibia on the femur. It also provides secondary stabilization to varus/valgus rotation and internal/external rotation of the knee. Besides, ACL is a critical stabilizer that prevents hyperextension of the tibia. The ACL has two discrete bands: an anteromedial and a posterolateral bundle, with an intermediate band occasionally present. When the knee is fully extended, the femoral attachment of the anteromedial bundle is anterior to the attachment of the posterolateral bundle, which is taut. ${ }^{[4]}$
Rupture of the anterior cruciate ligament (ACL) is the most common and one of the most serious ligament injuries in the knee joint. It affects mainly young and active people. Anterior cruciate ligament (ACL) injury is one of the most dreaded injuries among athletes. ${ }^{[5]}$ The present study was conducted to assess cases of anterior cruciate ligament reconstruction surgery in adult patients.

\section{Subjects and Methods}

The present study was conducted in the department of Orthopedics. It comprised of 72 patients who underwent anterior cruciate ligament reconstruction surgery of both genders. All were informed regarding the study and written consent was obtained.

General data such as name, age, gender etc. was recorded. A through clinical examination was done in patients. CT scan was performed in all patients. Results thus obtained were subjected to statistical analysis. $\mathrm{P}$ value less than 0.05 was considered significant.

\section{Results}

Table 1: Distribution of patients
\begin{tabular}{|l|l|l|}
\hline Gender & Males & Females \\
\hline Number & 48 & 24 \\
\hline
\end{tabular}

[Table 1] shows that out of 72 patients, males were 48 and females were 24 . 


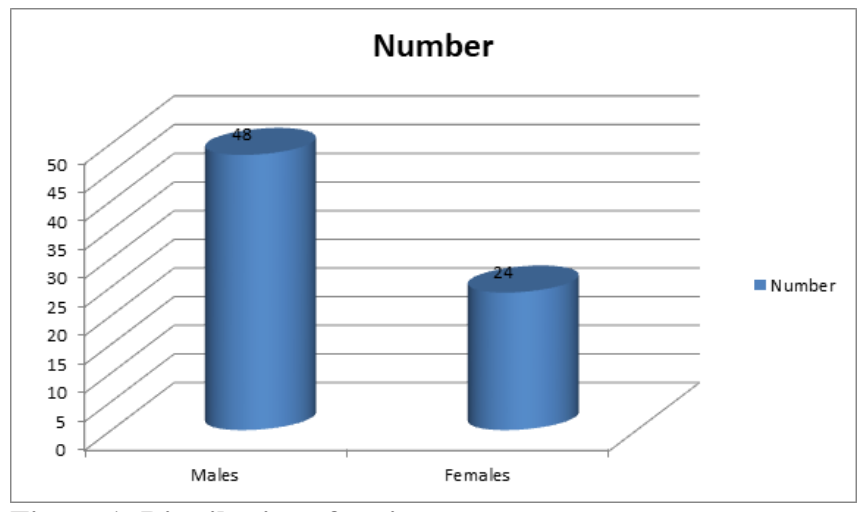

Figure 1: Distribution of patients

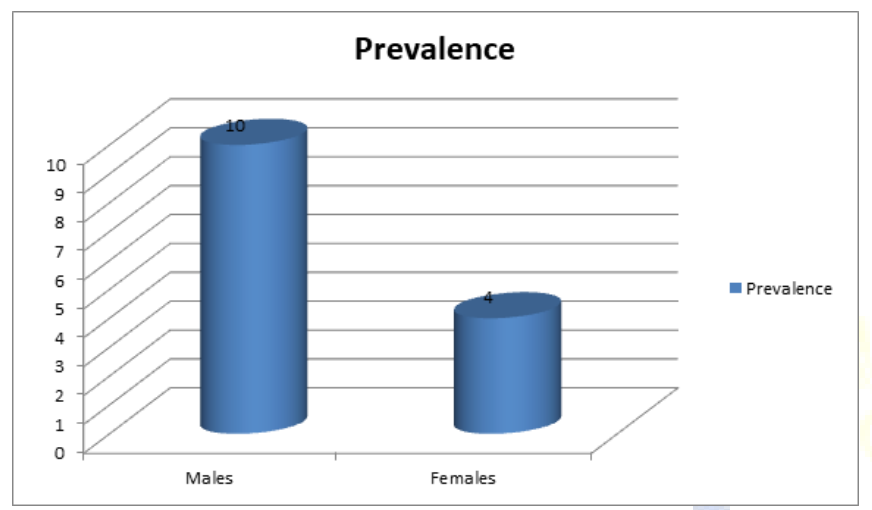

Figure 2: Prevalence of infection in ACL surgery cases

[Figure 2] shows that out of 72 patients, infection was present in 10 males and 4 females.

\begin{tabular}{|c|c|c|}
\hline Parameters & Number & P value \\
\hline BPTB graft & 3 & \multirow{5}{*}{0.01} \\
\hline STG graft & 5 & \\
\hline Obesity & 11 & \\
\hline Smoking & 6 & \\
\hline Diabetes mellitus & 4 & \\
\hline
\end{tabular}

[Table 2, Figure 3] shows that risk factors for ACL surgery was BPTB graft in 3, STG graft in 5 cases. Obesity was seen in 11 , smoking in 6 , and diabetes mellitus in 4 . The difference was significant $(\mathrm{P}<0.05)$.

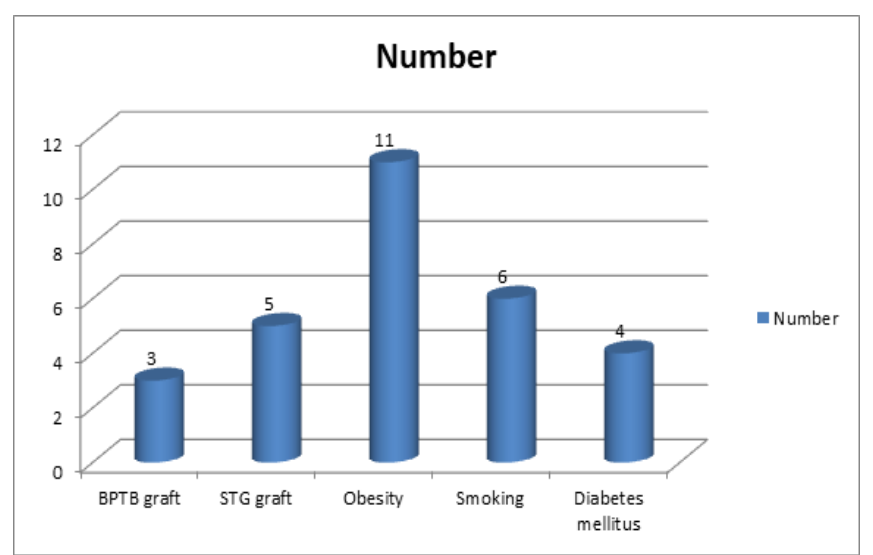

Figure 3: Assessment of risk factors

\section{Discussion}

ACL tear in sports is quite frequent and they seriously affect players' career with short-term and long-term consequences. ${ }^{[6]}$ It has also been seen that ACL injuries are very invalidating events that require surgical treatments and keeps majority of players out of competition at least four months every season. ACL injuries in team sports, the exact mechanism of these injuries remains unclear. Understanding the joint kinematics and loading patterns that lead to injury is essential. ${ }^{[7]}$

The injury causes knee joint instability which in turn leads to decreased knee function. ACL injury is often associated with concomitant damage of other joint structures, including meniscus tears and chondral lesions. Since it has been documented that ACL injury places the patient at risk for early osteoarthritis, ACL reconstruction (ACLR) has been widely advocated as a treatment method of choice. ${ }^{[8]}$ The present study was conducted to assess cases of anterior cruciate ligament reconstruction surgery in adult patients.

In this study, out of 72 patients, males were 48 and females were 24 . Wang et al, ${ }^{[9]}$ conducted a study on 56 patients who underwent anterior cruciate ligament reconstruction surgery. Infection was suspected when features of fever, knee swelling/effusion, local rise of temperature, pain out of proportion to the surgery, loss of regained knee movements, etc., were present after ACLRS. Out of 56 patients, males were 36 and females were 20 . Out of 56 patients, infection was present in $12(21 \%)$, males were 7 (12.5\%) and females were $5(8.92 \%)$. Risk factors were BPTB graft in 4 , STG graft in 8 . Presence of smoking was seen in 10 , obesity in 5 and diabetes mellitus in 6 .

We found that out of 72 patients, infection was present in 10 males and 4 females. Risk factors for ACL surgery was BPTB graft in 3, STG graft in 5 cases. Obesity was seen in 11 , smoking in 6 , and diabetes mellitus in 4 . Kim et al, ${ }^{[10]}$ found that 8 patients out of 26 were having the tubercular infection after the ACLRS without any preoperative evidence of tuberculosis. At the final follow up, the mean side-to-side difference using KT 1000 arthrometer was 2.29 $\mathrm{mm}$ (range $0 \mathrm{~mm}-4 \mathrm{~mm}$ ) which was similar to those in our uncomplicated cases $1.9 \mathrm{~mm}$ (range $0 \mathrm{~mm}-5 \mathrm{~mm}$ ). However, the mean Lysholm score was lower 79.2 \pm 10.52 (range 48-92).

McLean et $a l,{ }^{[11]}$ found that there was contact at the assumed time of injury in 11 of the 39 cases ( 5 male and 6 female players). Four of these cases were direct blows to the knee, all in men. Eleven of the 22 female cases were collisions, or the player was pushed by an opponent before the time of injury. The estimated time of injury, based on the group median, ranged from 17 to 50 milliseconds after initial ground contact. The mean knee flexion angle was higher in female than in male players, both at initial contact $\left(15^{\circ} \mathrm{vs} 9^{\circ}, \mathrm{P}=.034\right)$ and at 50 milliseconds later $\left(27^{\circ} \mathrm{vs}\right.$ $\left.19^{\circ}, \mathrm{P}=.042\right)$. Valgus knee collapse occurred more frequently in female players than in male players. 


\section{Conclusion}

Authors found that ACL injury is common among sports person. Risk factors reported were diabetes mellitus, smoking and obesity.

\section{References}

1. Schollin-Borg M, Michaëlsson K, Rahme H. Presentation, outcome, and cause of septic arthritis after anterior cruciate ligament reconstruction: A case control study. Arthroscopy 2003;19:941-7.

2. Van Tongel A, Stuyck J, Bellemans J, Vandenneucker H. Septic arthritis after arthroscopic anterior cruciate ligament reconstruction: A retrospective analysis of incidence, management and outcome. Am J Sports Med 2007;35:1059-63.

3. Frank M, Schmucker U, David S, Matthes G, Ekkernkamp A, Seifert $\mathrm{J}$, et al. Devastating femoral osteomyelitis after anterior cruciate ligament reconstruction. Knee Surg Sports Traumatol Arthrosc 2008;16:71-4.

4. Judd D, Bottoni C, Kim D, Burke M, Hooker S. Infections following arthroscopic anterior cruciate ligament reconstruction. Arthroscopy 2006;22:375-84
5. McAllister DR, Parker RD, Cooper AE, Recht MP, Abate J. Outcomes of postoperative septic arthritis after anterior cruciate ligament reconstruction. Am J Sports Med 1999;27:562-70.

6. Stucken C, Garras DN, Shaner JL, Cohen SB. Infections in anterior cruciate ligament reconstruction. Sports Health 2013;5:553-7.

7. Brophy RH, Wright RW, Huston LJ, Nwosu SK; MOON Knee Group, Spindler KP, et al. Factors associated with infection following anterior cruciate ligament reconstruction. J Bone Joint Surg Am 2015;97:4504.

8. Kursumovic K, Charalambous CP. Graft salvage following infected anterior cruciate ligament reconstruction: A systematic review and meta-analysis. Bone Joint J 2016;98-B:608-15.

9. Wang C, Ao Y, Wang J, Hu Y, Cui G, Yu J, et al. Septic arthritis after arthroscopic anterior cruciate ligament reconstruction: A retrospective analysis of incidence, presentation, treatment, and cause. Arthroscopy 2009;25:243-9.

10. Kim SJ, Postigo R, Koo S, Kim JH. Infection after arthroscopic anterior cruciate ligament reconstruction. Orthopedics 2014;37:47784.

11. McLean SG, Huang X, Van Den Bogert AJ. Association between lower extremity posture at contact and peak knee valgus moment during sidestepping: implications for ACL injury. Clin Biomech (Bristol, Avon). 2005;20:863-870.

Copyright: (C) the author(s), 2019. It is an open-access article distributed under the terms of the Creative Commons Attribution License (CC BY 4.0), which permits authors to retain ownership of the copyright for their content, and allow anyone to download, reuse, reprint, modify, distribute and/or copy the content as long as the original authors and source are cited.

How to cite this article: Sharma SC. Assessment of Cases of Anterior Cruciate Ligament Reconstruction Surgery- A Clinical Study. Asian J. Med. Res. 2019;8(3):OR06-OR08.

DOI: dx.doi.org/10.21276/ajmr.2019.8.3.OR2

Source of Support: Nil, Conflict of Interest: None declared. 